\title{
INTERPRETAÇÃO ECOLÓGICA DOS FORAMINÍFEROS DE SEDIMENTOS MODERNOS DA BAÍA DE SEPETIBA E ADJACENCIAS, RIO DE JANEIRO
}

\author{
Kenitiro Suguio \\ Instituto de Geoclências - Univ, de Š̃o Paulo (USP) \\ Elãene M. Vieira \\ Pontificia Univ. Catolica de Campinas, SP (PUC) \\ José H. Barcelos \\ Inst. de Biologia - Univ. Est. de Campinas (UNICAMP) \\ Marietta S. Silva \\ Pós-Graduanda do Instituto Oceanografico (USP)
}

In Sepetiba bay (State of Rio de Janeiro), a semi-confined, $305 \mathrm{~km}^{2}$ salt-water body, the present sedimentation is essentially clastic. From these sedimentary deposits, 92 samples have been collected and analysed which have allowed us to investigate the following parameters: benthonic foraminifera / planktonic foraminifera ratios, physical conditions of the foraminifera (size, wall thickness and

\section{ABTRACT}

abrasion degreel, and the diatom content of the samples.

Six dominant species of foraminifera have been identified in the studied area: Ammonia beccarii Liné in thirty-eight samples, Buliminella ele. gantissima Orbigny in seventeen samples, Textularia $s p$. in fourteen samples, Bulimina marginata Orbigny in two samples, Reophax sp. and Arenoparrella mexicana Kornfeld in one sample. Thus, three principal biofacies and three less important biofacies are characterized by foramini* feral content of the sediments.

These results confirm the importance of foraminiferal synecological studies in understanding water circulation dynamics and sedimentary dispersion on a regional level. Moreover, it has been verified that the water-oxygen content of the ecosystem is reflected by the foraminiferal content of the sediments.

\section{RESUMO}

Na baía de Sepetiba, corpo de água salgada semiconfinado com cerca de $305 \mathrm{~km}_{2}$ a sedimentação atual é de natureza essencialmente clástica. Destes sedimentos, foram coletadas 92 amostras, cujas análises permitiram conhecer a relaça entre os foraminíferos bentônicos e foraminíferos planctônicos, suas condiçðes físicas (tamanho, espessura e desgaste) e o estado de conservação das diatomáceas.

Foram determinadas seis espécies dominantes de foraminíferos, na área estudada: Ammonia beccarii Liné em trinta e oito amostras, Buliminella elegantissima Orbigny em dezessete amostras, Textularia sp. em catorze amostras, Bulimina marginata Orbigny em duas amostras, Reophax sp. e Arenoparrella mexicana Kornfeld em uma amostra. Deste modo, três grandes biofácies e outras três menos importantes foram caracterizadas pelo

\section{INTRODUÇÃO}

A baía de Sepetiba é limitada ao norte e leste pelo contingente, ao sul pela restinga de Marambaia, e a oeste por um cordão de ilhas que se estende desde as proximidades da ponta de Pombeba até a ilha da Madeira (Fig. 1). A sua configuração atual foi definida durante o Quaternário, quando flutuações do nível marinho foram verificadas ao longo da costa sul-brasileira. Segundo Suguio et al, (1977), a última transgressão (Transgressão Santos), com níveis máximos há 5000 e 3300 anos B.P., separados por um mínimo há 3800 anos B.P., elevou o nível marinho de alguns metros em relação ao atual, propiciando o desenvolvimento das atuais planíceis costeiras, estabelecendo a linha da costa sul paulista caracterizada por uma contínua progradação. Excluemse deste quadro o setor norte do litoral paulista e sul fluminense, que simulam costas de submersão, com desenvolvimento de costoes e praias do bolso.

Uma das teições geomorfológicas típicas da área de Sepetiba é a presença de restinga de Marambaia, situada entre afloramentos cristalinos, delimitando uma zona lagunar em fase de colmatação.

PONÇANO (1976) estabeleceu o padrão de circulaçăo das águas e a dinâmica sedimentar, bem como a história de formação desta baía, no seu estudo de avaliação de viabilidade de implanta. ção de instalações portuárias.

Objetivando ampliar os conhecimentos sobre a área. foi aqui estudada a conteúdo em foraminíferos dos sedimentos.

Os resultados obtidos confirmam a importância de estudos sinecológicos de foraminíferos na compreensão da dinâmica das águas, especialmente quando avaliados ao nível de informaçóes regionais. Além disso, os reflexos das variações do teor de oxigênio das águas no arcabouço do ecossistema e no seu conteúdo em foraminíferos foram verificados. estrutura das assembléias de foraminíferos, acrescidas de dados sobre diatomáceas. Foram analisadas 92 amostras, sendo 73 cedidas pelo Instituto de Pesquisas Tecnologicas $S / A$ e 19 coletadas pelos autores, com a finalidade de conhecer as variaçoes da relação entre foraminúferos bentônicos e foraminíferos planctônicos, estado físico (tamanho, espessura e desgaste) das testas de foraminíferos e o grau de conservação das diatomáceas.

Os autores agradecem ao Instituto de Pesquisas Tecnológicas S/A e a Portobrás pelas amostras cedidas para este estudo. Agradecem também à FAPESP (Fundação de Amparo à Pesquisa do Estado de São Paulo) pela concessão de bolsa de iniciação científica à Srta. Marieta S. Silva. 
CIRCULAÇÃo dE ÁGUAS E DINÂMICAS SEDIMENTAR

De acordocom PONÇANO (op.cit.), as águas da baía de Sepetiba ligam-se ao oceano por duas zonas: por entre o cordao de ilhas que formam o seu limite oeste e pelos canais que desaguam na barra de Guaratiba. Em termos batimétricos, ocorre um canal com profundidade de duas a três dezenas de metros, que vem da baía de Ilha Grande e o continente e, penetra dentro da baía de Sepetiba por um canal principal que passa entre as ithas de Itacuruçá e Jaguánum, e por canais secundários entre o continente e a ilha de Itacuruçá, e ainda, entre a ilha do Jaguanum e a ponta da Pombeba. Todos os canais correspondem aos entalhes fluviais ligados à fase de regressão marinha contemporânea à ultima fase glacial.

No interior da baía, as profundidades diminuem gradativamente de oeste para leste e do centro para as bordas, e, próximo à barra de Guaratiba, eståo em torno de 1 a $2 \mathrm{~m}$. Entre ilha Grande e morro de Marambaia configura-se um alto topográfico; conseqüentemente, as lâminas de água são aí mais rasas que as do canal de ligação entre as baías de Ilha Grande e de Sepetiba.

PONÇANO (op. cit.) admite três fontes oceânicas principais para os sedimentos que entram na baía de Sepetiba. A mais importante está relacionada à baía de Ilha Grande. A segunda provém da regiaxo entre a ilha Grande e o morro da Marambaia. Os sedimentos provenientes dessas áreas-fontes juntam-se ao entrar na barra, circulando entre o morro da Marambaia e a ilha de Jaguanum, e entre as ilhas do Batuque e Ittacuruçá, seguindo pelo canal Itá, desembocando no saco da Coroa Grande. A terceira fonte, menos expressiva, é originária dos canais da barra de Guaratiba, que possibilitam maior aeração e movimentação na face interna da restinga da Marambaia, juntando-se, em seguida, à área de agitação entre o morro da Marambaia e ilha do Jaguanum.

Conseqüentemente, as características da baía de Sepetiba são francamente marinhas, sendo a contribuiçăo de detritos continentais, de origem fluvial, limitada e restrita à faixa nordeste da baía, nas proximidades das desembocaduras de canais e rios.

\section{TIPOS DE SEDIMENTOS}

A coluna sedimentar sotoposta aos sedimentos atuais da baía de Sepetiba, interpretada por PONCCANO (op. cit.), mostra basicamente três tipos básicos: fluviais, de canais de maré $e$ de mangue. Os sedimentos fluviais dispoem-se em corpos lenticulares, que devem representar seções de canais, com gradação de sedimentos mais grosseiros (seixos), na base, para m..'s finos (areias) em direção ao topo. $u$ ambiente fluvial é representido também por corpos de sedimentos niais sílticos e argilosos típicos de planície inundação. Os depósitos de mangt. são representados pelos sedimentos argilosos e arenosos com freqüientes inclusðes de restos vegetais e lentes arenosas incluídas nesses sedimentos, são interpretadas como depósitos de preenchimento de canais de maré. Além disso, segundo o mesmo autor, essa seqüência transgressiva foi profundamente erodida, tendo serviço de substrato à esculturação de uma drenagem hoje submersa em virtude da elevação do nível marinho contemporânea ao estádio interglacial RissWürm.

Os depósitos e os eventos acima descritos, juntamente com as condiçóes dinâmicas atuais, determinam $o$ padrão de distribuição dos sedimentos recentes na baía de Sepetiba (Fig. 1).

\section{ANÁLISE DE MICROORGANISMOS}

As 92 amostras coletadas foram analisadas conforme métodos comumente empregados em estudos desta natureza. Inicialmente, foram retirados 10 c.c. de sedimento de cada amostra, para o estudo dos foraminíferos $e$ análise do estado de conservação das diatomáceas. O sedimento ligeiramente endurecido por ressecação foi desagregado e separado em peneiras de malhas $0,062-0,150$ e $0,250 \mathrm{~mm}$. As fraçðes obtidas foram flutuadas em tetracloreto de carbono e, após filtradas, os foraminíferos e as diatomáceas foram contados, após triagem e montagem em lâminas especiais.

Em seguida foram calculadas as frequîencias de cada taxa, e o total de testas por assembléia seguido de identificação sistemática das espécies, com base em LOEBLICH e TAPPAN (1964). Para as análises ecologicas, todos os resultados dos cálculos realizados foram recalculados $e$ expressos em 1 c.c. de sedimento úmido.

Os caracteres - de preservação do material, tamanho dos espécimes e espessura das paredes foram quantificados.

As bases téricas dos critérios ecológicos empregados foram segundo PETRI e VIEIRA (1975), segundo os parâmetros: (a) abundância relativa de espécimes (ARE), (b) indice de dominância (ID), (c) diversidade específica (DE) (d) relação foraminíferos aglutinados/foraminíferos hialinos / foraminíferos calcários porcelânicos, (e) distribuiçăo de foraminíferos planctônicos, (f) tamanho dos espéci. mes. $(\mathrm{g})$ amplitude das areas de dominância (AAD) e (h) distribuição (le diatomáceas.

\section{RESULTADOS E DISCUSSÕES}

\section{Abundância relativa de espécimes (A.R.E.)}

Os valores de ARE, expressos em 1 c.c. de sedimento úmido, variaram entre 7 e 2058 espécimes, permitindo agrupar as amostras em dois conjuntos: (a) inferior a 500 espécimes e (b) superior a 500 espécimes (Fig. 2). Apenas quatro amostras apresentaram valor de A.R.E. superior a 1000 .

De forma inesperada, em seu conjunto, a ARE nåo revelou relaçăo direta com o tipo de sedimento de fundo (Fig. 1) e, por conseguinte, não é explicável pela taxa de sedimentação. Sua explicação prende-se ao padrão de produtividade primária de foraminíferos (PETRI e VIEIRA, op. cit.). Esta produtividade é basicamente dependente do teor de nutrientes disponíveis.

PONÇANO (op. cit.) salientou a reduzida influência fluvial nesta baía, fornecendo o argumento básico que explica os baixos valores de ARE, isto é, baixa produtividade de espécimes por deficiência de nutrientes. Nas áreas sem ressurgência, o continente é a fonte básica de alimentos, fornecidos através de rios, para o desenvolvimento de vida nos oceanos. Sendo esta baía eminentemente de carater marinho, os resultados encontrados seriam os esperados como padrão normal de comportamento ecológico.

\section{Indice de dominância (I.D)}

Os valores deste parâmetro definiram os biótopos: A (inferior a 29,9\%), B (entre 30 e $49,9 \%$ ) e C (superior a $50 \%$ ) (Fig. 3).

O ID, que indica o status evolutivo de uma comunidade, tende a ser elevado em biótopos com instabilidade ambiental (física ou química), porque ela năo atinge o clímax em tais ambientes.

Os resultados mostraram ampla variaçăo do índice de amostras analisadas, expressando a imaturidade das comunidades e o caráter instável da área. As particularidades de cada amostra salientaram-se, então, em detrimento do nível de semelhança do conjunto.

Em nivel de detalhe maior, onde o índice deveria ser reduzido pela baixa energia das águas, em locais de fundo argiloso e síltico (Fig. 1) e biótopos A e B (Fig 3), constatou-se uma situação inversa. Portanto, a maior estabilidade física do ambiente, expressa em energia ambiental, não coaduna com os elevados valores do índice de 
dominância na área leste da baía. Tais biótopos situam-se onde PONÇANO (op. cit.) registrou os maiores valores do teor de matéria orgânica nos sedimentos, tendo afirmado: ... "mercê da intensa movimentação de que é sede, a baía de Sepetiba apresenta boa aeração, não se esboçando ambiente euxínico senão na sua metade leste".

A aeração deficiente em um corpo de água atua como fator limitante à proliferação da maioria das espécies, dando oportunidade a poucas espécies tolerantes dessas condições, que tendem a assumir caráter dominante. Em tais locais, o ID torna-se elevado, conferindo com os dados em interpretação. No restante da baía há boa aeração, então, a dominância é menor, constituindo o biótopo $\mathrm{C}$ que abrange maior área.

\section{Diversidade especifica (D.E.) de foraminiferos bentônicos}

Os resultados de estudo da DE total de foraminíferos bentônicos permitiram reconhecer três intervalos: (a) inferior a 10 espécies, (b) 10 a 24 espécies e (c) 25 a 43 espécies. Eles determinaram os biótopos representados na fig. 4. A reduzida $\mathrm{DE}$, no extremo leste da baía, confere com os resultados de ID nas mesmas amostras, podendo ser associada à causa já exposta, ou seja, condição euxínica. No restante da área, onde há boas condiçōes de aeração, as variaçðes de diversidade específica nå atingiram os valores abaixo de 10 especies, exceto em duas amostras. Os valores da área central da baía (biótopo C), sugerem ser esta a área de melhores condiçôes de estabilidade e aeração.

O mapa de distribuição do diâmetro médio dos sedimentos clásticos (Fig. 1) indica que a maioria das amostras situadas nos biótopos $\mathrm{C}$ e $\mathrm{E}$ é constituída principalmente de silte, indicando menor energia do que do biotopo $D$, onde predominam areias grossas. A última situação, em particular, concorda com a afirmação de PONÇANO (op. cit.), segundo a qual, a baía seria sede de intensa movimentação, condiçăo esta associável a baixa estabilidade ambiental e conseqüentemente menor DE.

\section{Relação foraminiferos aglutinados} (F.A.)/foraminiferos calcários hialinos (F.C.H.) / foraminiferos calcários porcelânicos (F.C.P.)

Os resultados deste parâmetro para a baía de Sepetiba estão representados nas Figs. 5 e 6.

GREINER (1969 e 1974) estudou esta relaçao em oito estuários do golfo do México e constatou que a distribuiçăo destes três grupos está muito relacionada a variaçoes de salinidade. temperatura e teor de bicarbonato de cálcio. Acredita-se que as espécies aglutinadas possam construir suas testas em qualquer um dos ambientes marinhos ou de águas mixohalinas, e a sua dominância em águas pobres em bicarbonato de cálcio é devida à inabilidade das formas calcárias secretarem suas testas em tais lugares. As formas porcelânicas geralmente requerem supersaturação das águas em bicarbonato de cálcio e os hialinos formam-se em condiçðes intermediárias.

A amplitude das areas de distribuiçăo de foraminíferos com testas calcárias hialinas e a área restrita de ocorrência das formas aglutinadas explicam-se pelas condiçðes predominantemente marinhas da baía de Sepetiba, conforme já citado. A sedimentaça essencialmente clástica na baía serve de argumento à reduzida presença de $\mathbf{F} \mathbf{C}$ $\mathbf{P}$ nas amostras estudadas, considerando os postulados de GREINER (1974), que afirma serem eles dominantes em areas de elevado teor de bicarbonato de cálcio.

Distribuição de foraminiferos planctô. nicos Estes foraminíferos são extremamente raros e permitem apenas registrar a presença ou ausência nas amostras (Fig. 7). Este parâmetro confirma as informaçôes geológicas de que a zona oeste teria carater marinho mais acentuado. No entanto, tal caráter não exclui os demais fatores que limitam maiores concentraçðes de formas planctônicas, tais como proximidade da costa e profundidade da água na área (PETRI e VIEIRA, op. cit.).

Os núcleos de ausência de formas planctônicas, entre as ilhas da Marambaia e Grande, coincidem com pequenas elevaçóes do substrato marinho, registradas pelas isóbatas.

Tamanho dos espécimes. Os termos pequeno, médio e grande correspondem as dimensðes dos espécimes retidos nas peneiras com as seguintes malhas: $0.062-0.150$ e $0.250 \mathrm{~mm}$, respectivamente. $O$ padrão de distribuição desses tamanhos está registrado na Fig. 8. Vê-se novamente, a baía dividida em dois biótopos: (a) zona leste, com testas pequenas e (b) zona oeste, com testas médias e grandes. exibindo maior variabilidade de tamanho.

Os autores lembram da necessidade de oxigênio no metabolismo biológico e associam o biotopo $\mathrm{A}$ às condiçós mais redutoras e o biótopo $\mathrm{B}$ às áreas de melhor aeração.

Espessura das paredes das testas. A Fig. 9 mostra como varia este parâmetro na área em estudo. Os padróes definidos praticamente se superpoem aos da fig. 8, sendo igualmente associados aos graus de aeração das águas.
Amplitude das áreas de dominância (AAD)

Seis diterentes espécies dominantes dividiram a área amostrada em compartimentos (Fig. 10). Excetuandose as espécies Reophax sp. (Amostra 159), Arenoparrella mexicana Kornfeld (Amostra 217) e Bulimina marginata Orbigny (Amostra 166 e 168), nas demais amostras, dominaram as seguintes espécies: Textularia sp. (14 amostras), Buliminella elegantissima Orbigny (17 amostras) e Ammonia beccarif Line (38 amostras), que permitiram reconhecer três biofácies:

(a) Biofácies Textularia sp., contendo poucos espécimes e espécies (DE menor que 10) com ID entre 35 e $79 \%$; abrangendo a faixa situada entre as ilhas da Madeira e do Bom Jardim, de maior influência fluvial. As condiçōes locais tendem a ser redutoras e o fundo é constituído de sedimentos clásticos finos.

(B) Biofácies Buliminella elegantissima Orbigny caracterizada por sensível aumento do número de espécies e de espécimes (DE maior que 10) com ID menor que $50 \%$, predominando testas pequenas e delgadas. Esta biofacies foi encontrada em áreas com 0 a $10 \mathrm{~m}$ de profundidade em substrato síltico, delimitada especialmente pelas amostras coletadas próximas à costa.

(c) Biofácies de Ammonia beccarii Liné caracterizada por grande aumento nas amplitudes dos parâmetros bibticos, as vezes, constituindo as populaçðes mais ricas em espécimes e espécies (DE entre 4 a 40 espécies) com ID geralmente inferior a 30 até $57 \%$. A espessura das testas é variável, predominando a espessura média. Esta biofácies ocorre em zona de maior aeração e maior energia, sendo o fundo caracterizado por substrato arenoso de diâmetros variáveis (Fig. 1).

Além destas, foi ainda reconhecida: (d) Biofácies Bulimina marginata Orbigny caracterizada por populaçðes mais ricas em espécimes e espécies (DE entre 40 a 43 espécies) com ID reduzida $(9,5$ a $12,7 \%)$. Nesta biofácies ocorre o predomínio de testas grandes com paredes de espessura média. Ela está situada em uma pequena área entre as ilhas Grande e Cutiatá.

$O$ arcabouco ecologico da baía de Sepetiba é do tipo primitivo, bastante simples, onde apenas três especies dominam em uma área de cerca de 305 $\mathrm{km}^{2}$. Considerando a amplitude da área, a variabilidade é bastante reduzida, sugerindo o mesmo para 0 comportamento ambiental. A Textularia sp. é uma espécie tolerante à baixa taxa de oxigênio, enquanto que Ammonia beccaril apresenta ampla tolerância a tipos de sedimentos e grau de energia das águas. A Buliminella elegantissima é condicionada pelo tipo 
de fundo. Há diferenças marcantes nas biofácies das partes leste e oeste da baía, porém estas não são acentuadas, permitindo ainda enquadrar a área toda em um tipo de ambiente ecologicamente pouco variável.

Distribuição de diatomáceas de água doce. Os resultados deste parâmetro acham-se resumidos na Fig. 11, revelando que há maior concentraçăo destas algas nas zonas de maior influência fluvial. Considerando-se a resistência de suas frústulas (silicosas) à destruição, a sua distribuição não modifica as deduções anteriores. Elas podem aportar em maior quantidade

GREINER, G.O.G. (1969) - Recent benthonic foraminifer: environment factors controlling their distribution Nature $223: 168-170$.

GREINER, G.O.G. (1974) - Enrironmental factors controlling the distribution of recent benthonic foramminifera - Breviora, 420 $35 \mathrm{p}$.

LOEBLICH, A.R. e H. TAPPAN (1964)

Protista - In: Treatise on the Invertebrade

Paleontology - Tomo C, Parte 2: 1-900.

PETRI, S. e E.M. VIEIRA (1975) - Métodos nos períodos de enchentes e a amostragem poderia ter coincidido com um desses períodos.

\section{CONSIDERAÇÕES FINAIS}

Os resultados do presente trabalho confirmam o valor da sinecologia de foraminíferos no entendimento da dinâmica das aguas costeiras, especialmente quando avaliados ao nível de informaçóes regionais.

Salienta-se a importância do teor de o oxigênio das águas na estrutura do ecossistema e no seu conteúdo em foraminíferos. PHLEGER e SOUTAR
(1973) estudaram foraminíferos bentô nicos de três locais do Pacífico oeste, em áreas com teores baixos de oxigênio, tendo concluído que o oxigênio não é um fator limitante para todas as espécies, havendo formas tolerantes a este tipo de ambiente. Os autores caracterizaram as populaçoes de foraminíferos pela sua alta dominância, baixa diversidade, espécimes relativamente pequenos e com testas finas. Essas mesmas feiçðes foram encontradas nos espécimes de biofácies da area leste, onde ocorrem as condições mais redutoras da baía de Sepetiba.

\section{BIBLIOGRAFIA}

de estudos paleoecológicos e as assembléias cenozóicas de foraminiferos de Caravelas, Babol. IG, Inst. de Geociências/USP, v. 6 : 109-127.

PHLEGER, K.B. e A SOUTAR (1973) - Productions of the benthic foraminifera in three East Pacific oxygem minima - $\mathrm{Mi}$ copaleontology 19 (1): $110-115$.

PONÇANO, W.L. (1976) - Sedimentação ATUAL NA BAIA DE Sepetiba, Estado do Rio de Janeiro - Um estudo para a ava- liaçăo de viabilidade geotécnica de implantaçåo de um porto - Dissertação de Mestrado, Inst. đe Geociências/USP, 2 vol. (Inédita)

SUGUIO, K.; L. MARTIN e J.M. FLEXOR (1977) -.. Sea-level fluctuations during the past 6,000 years along the coast of the São Paulo, Brazil - X Congresso Intern. do INQUA, Birmingham, Inglaterra, Preprint: $26 \mathrm{p}$. 


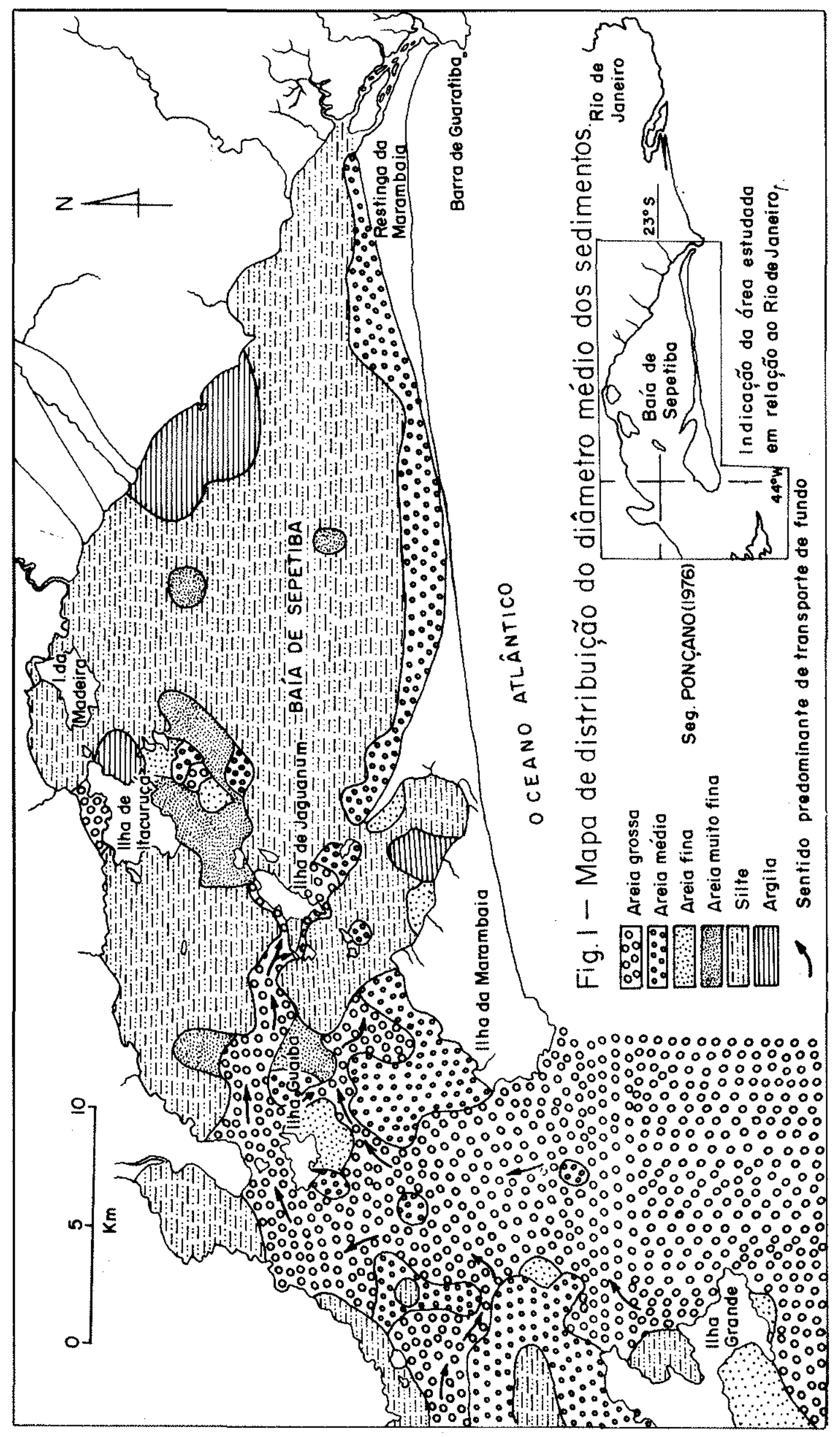




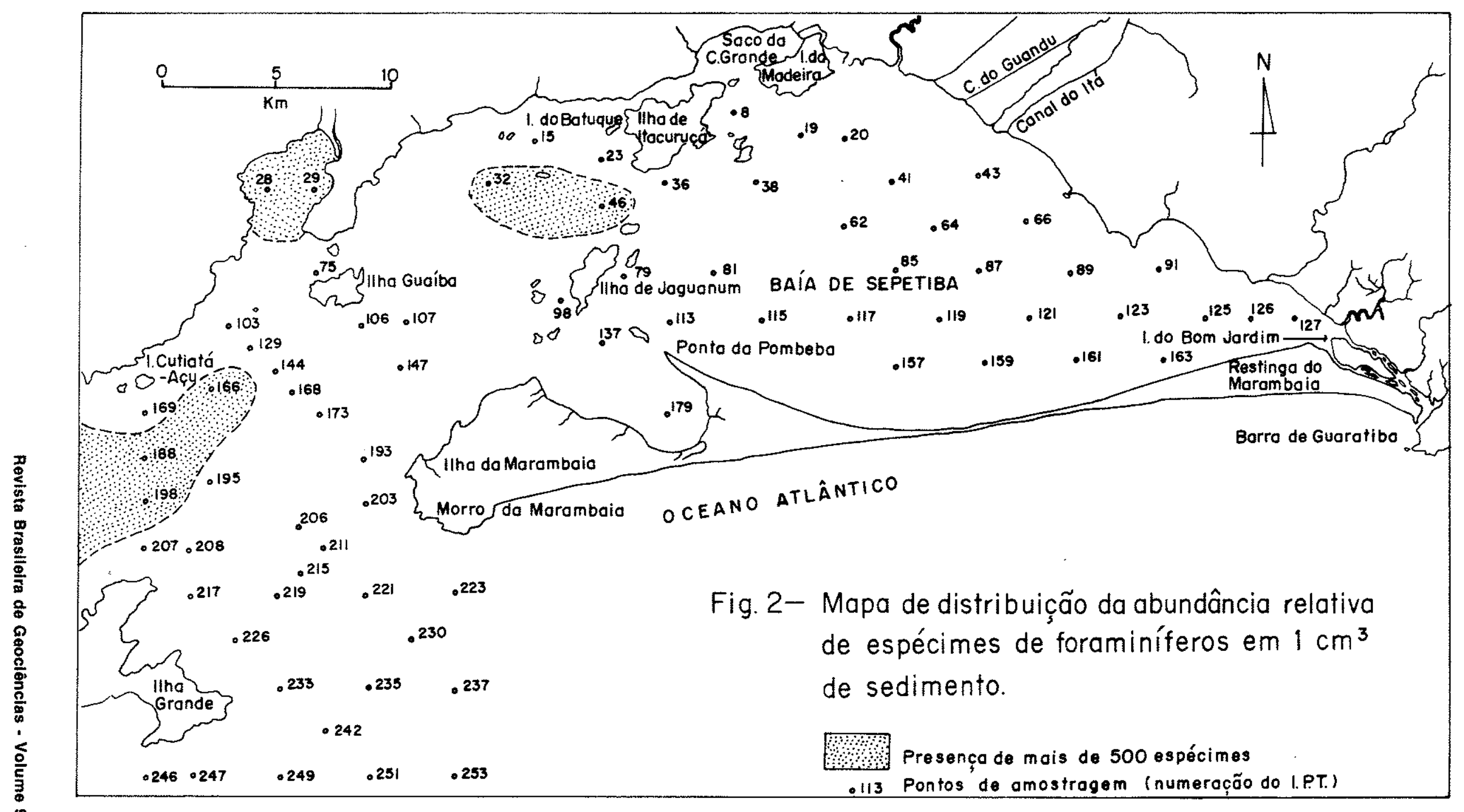




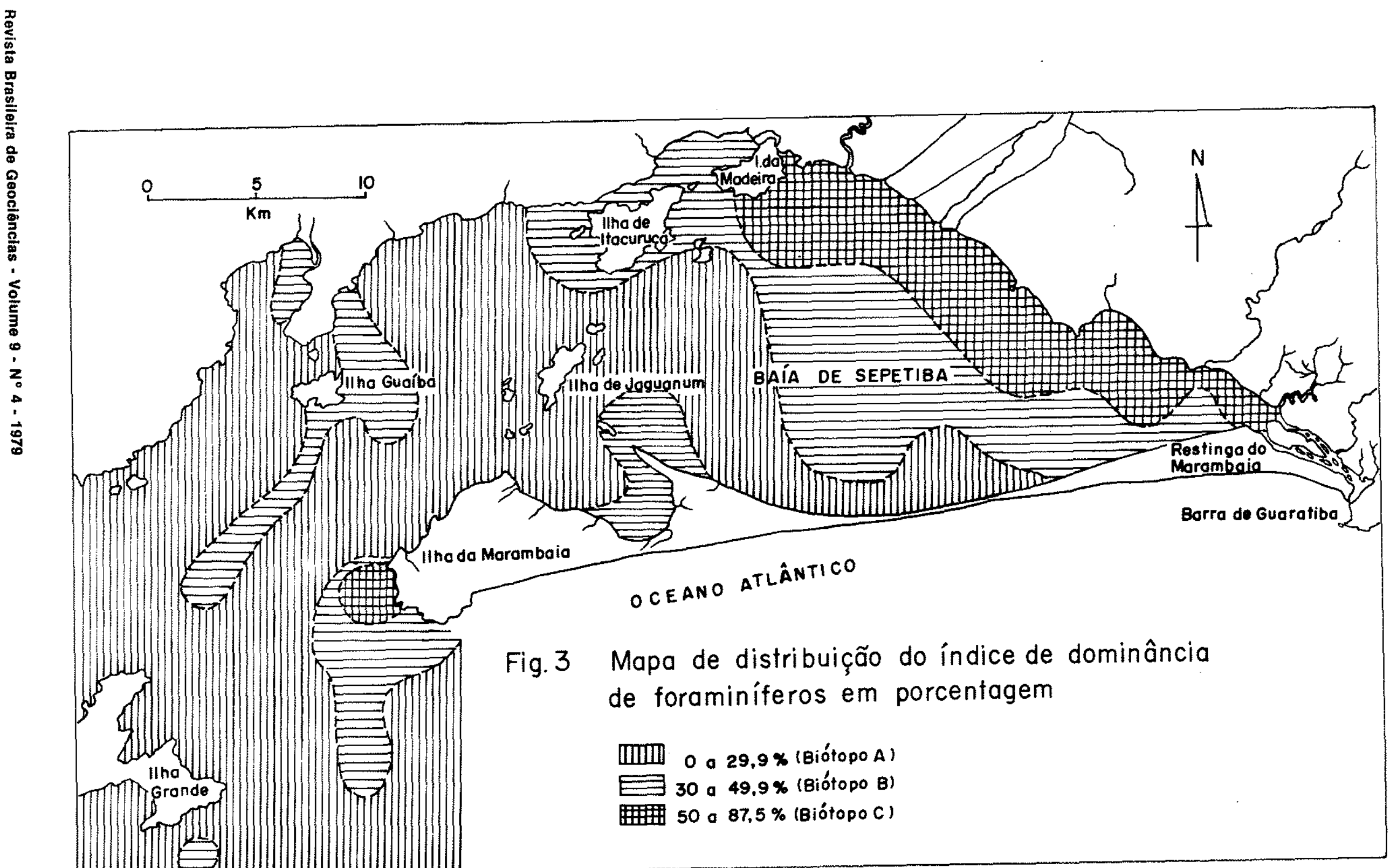




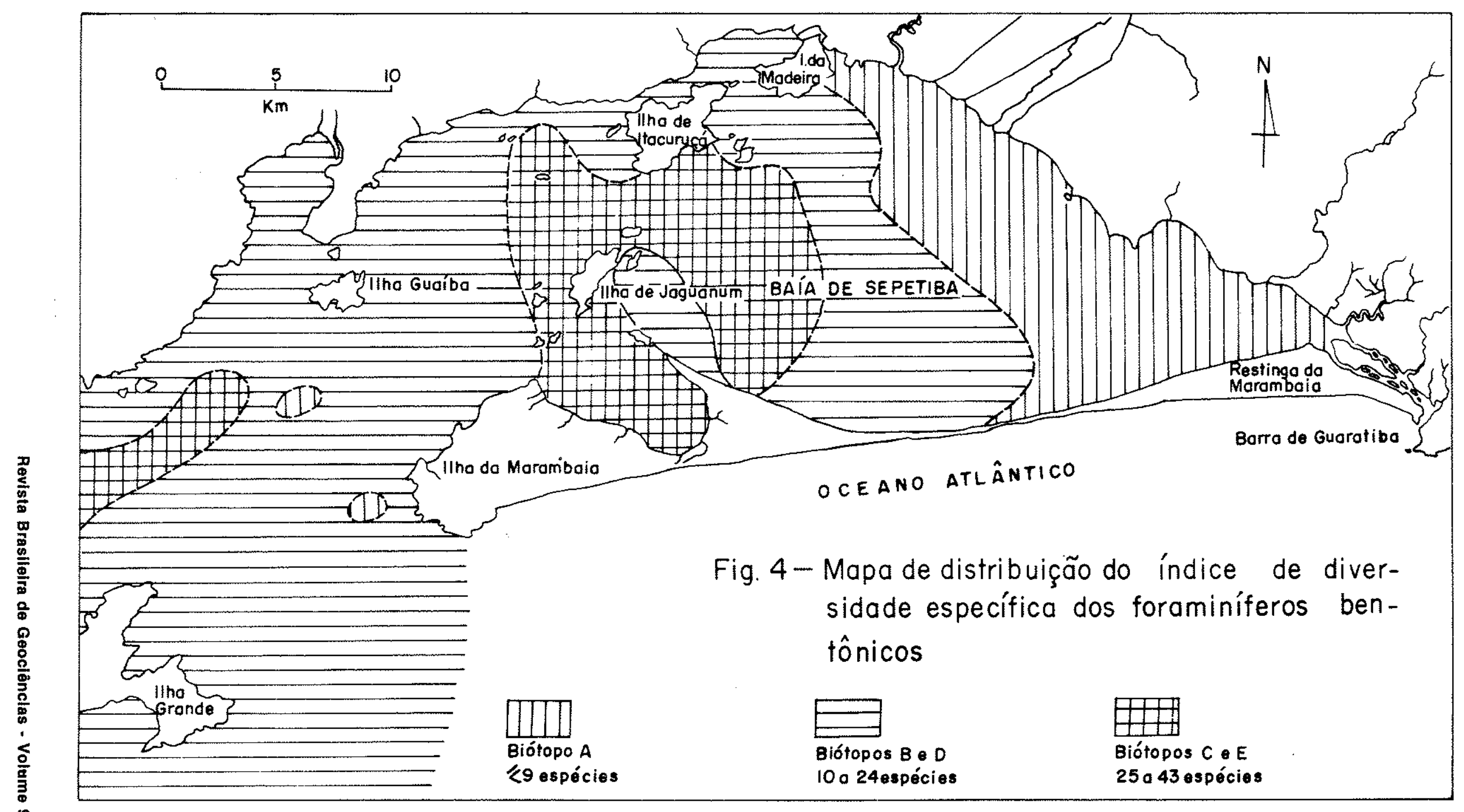




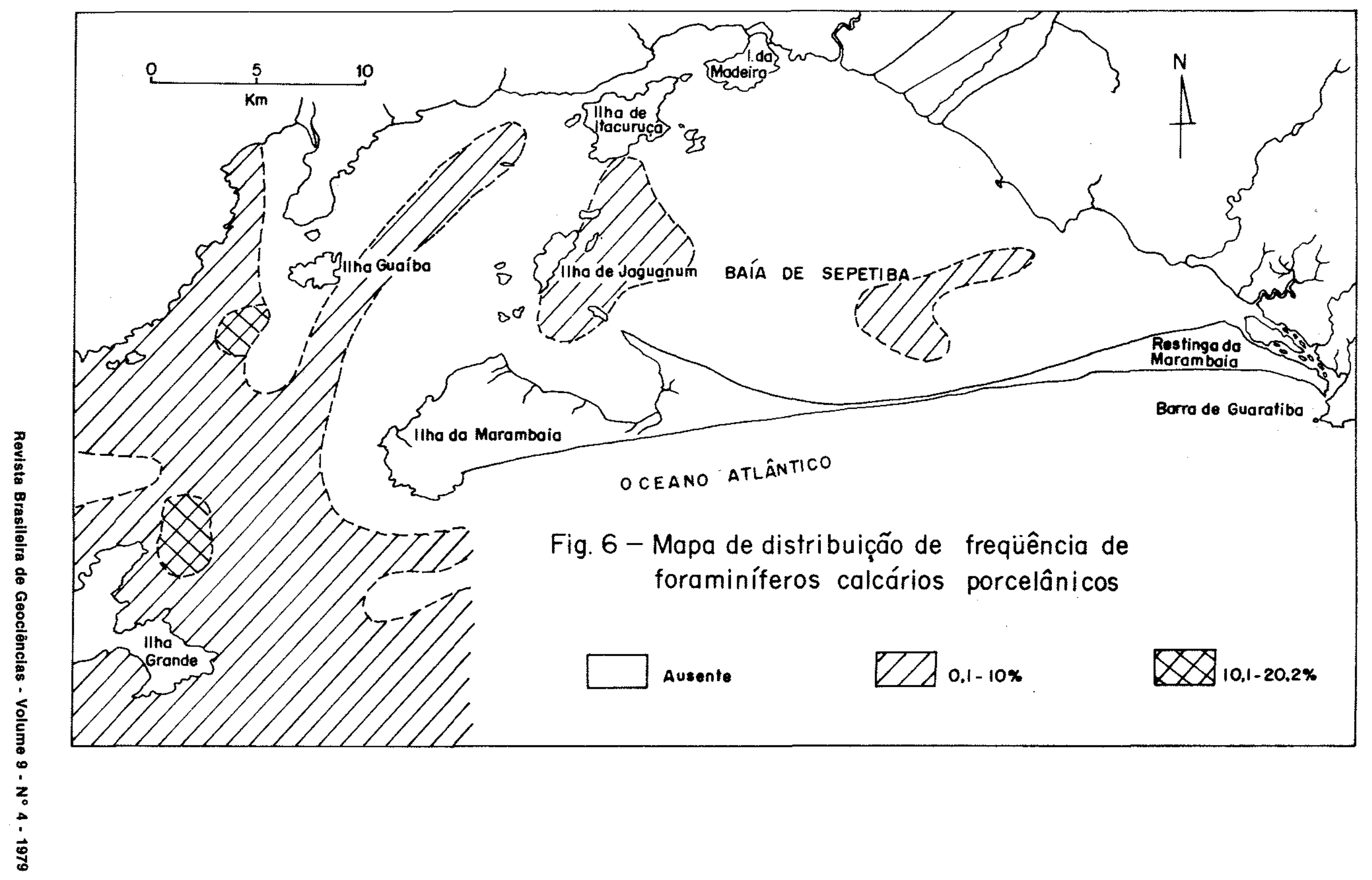




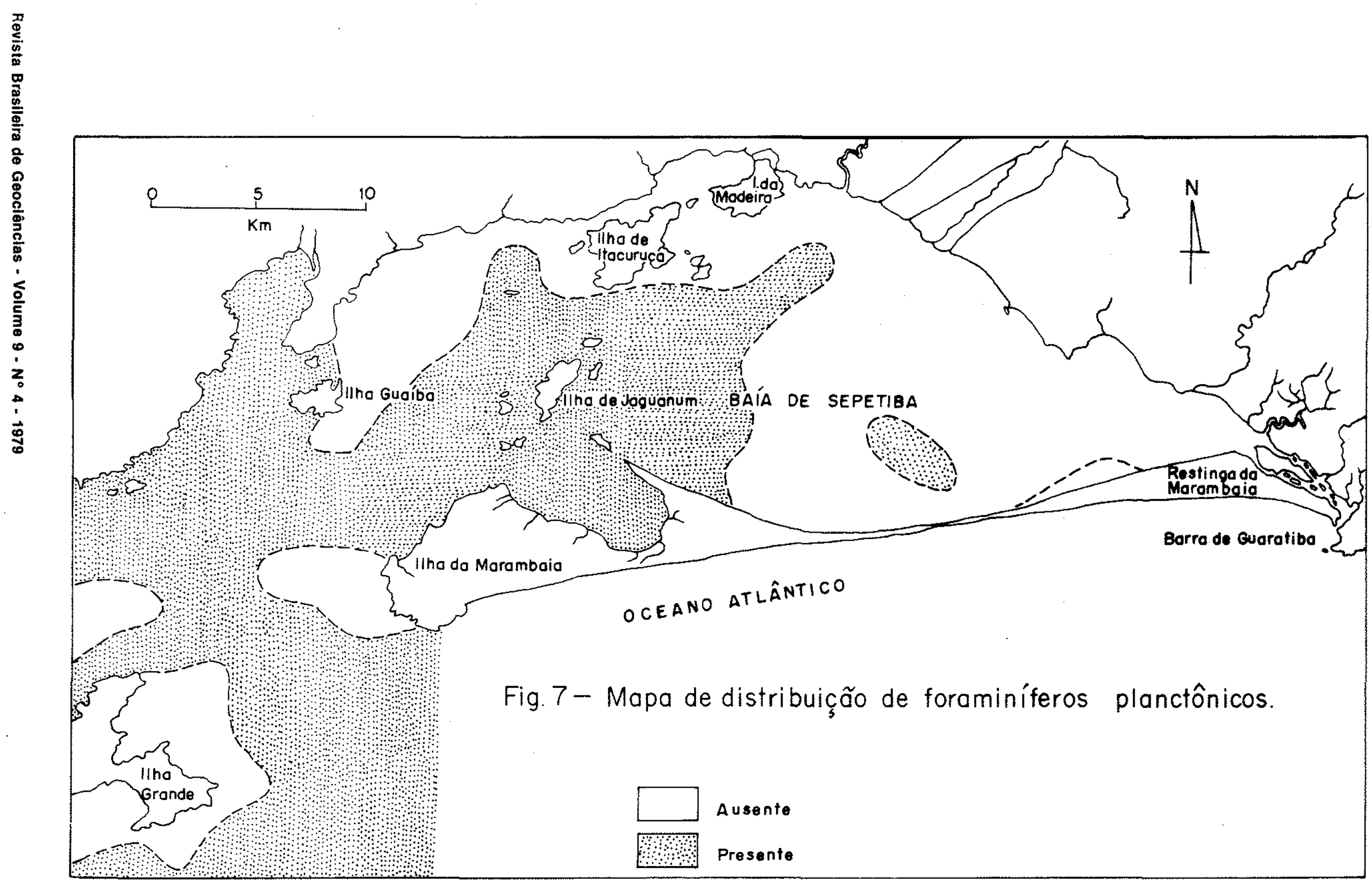




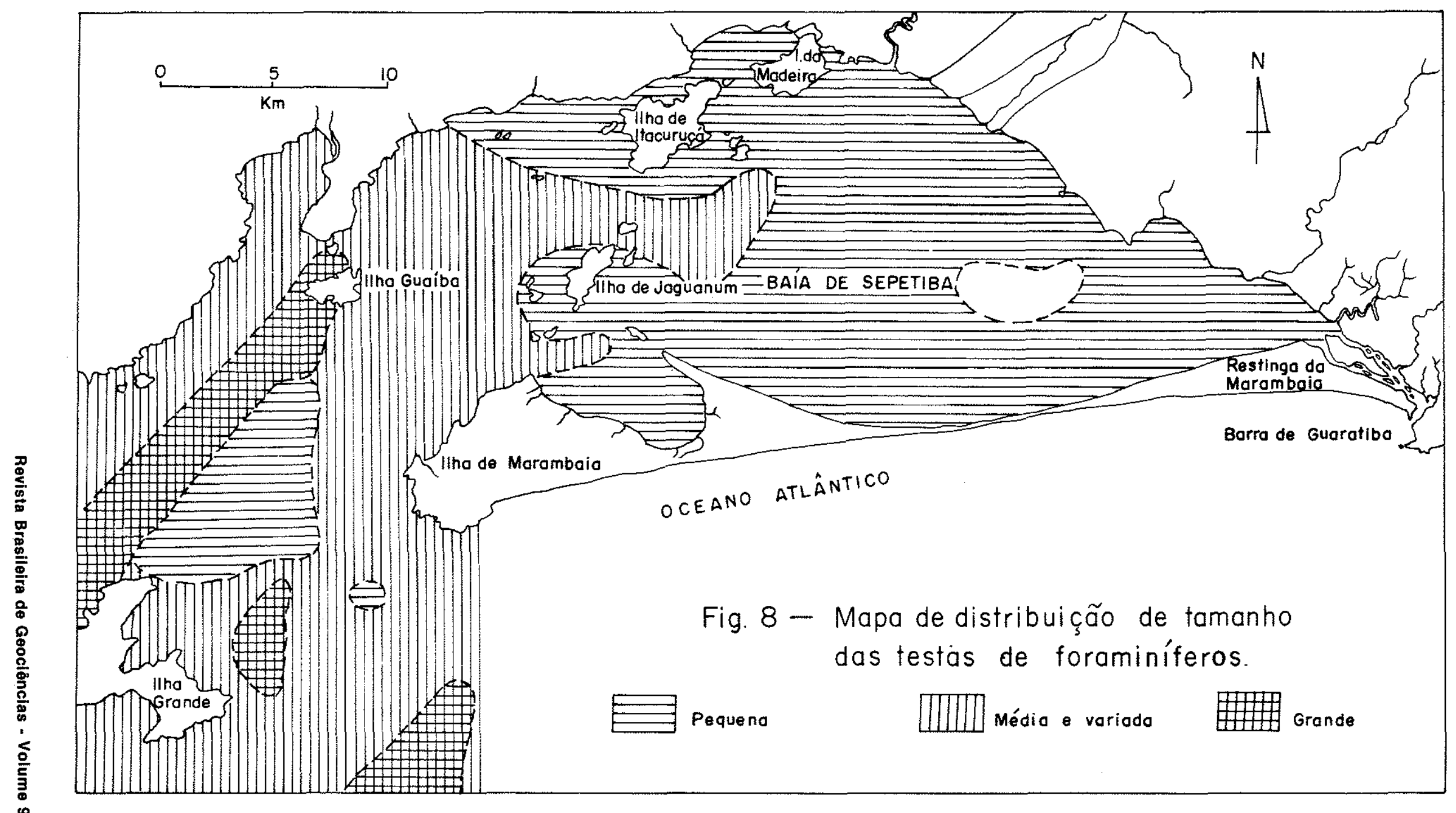




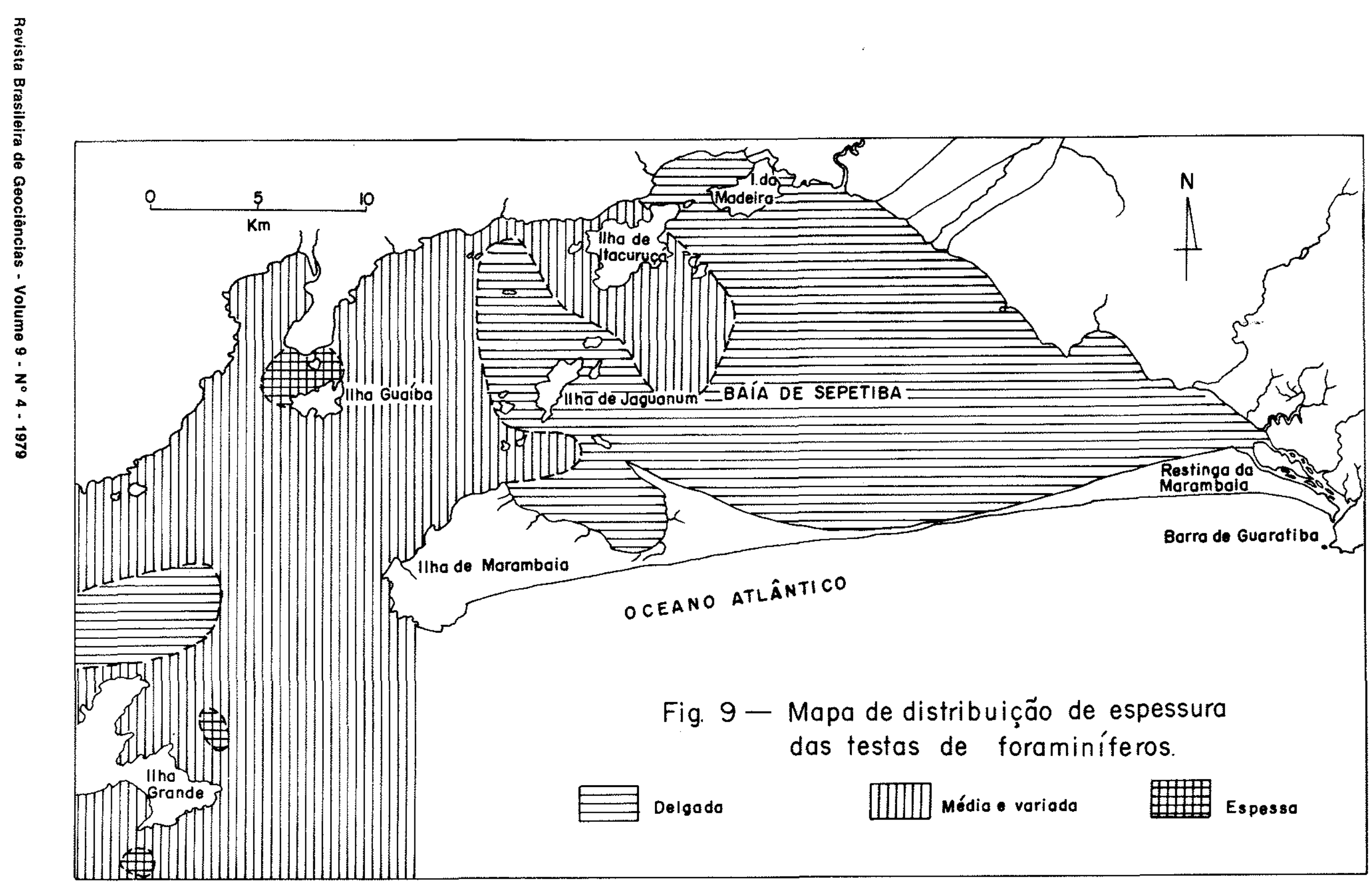




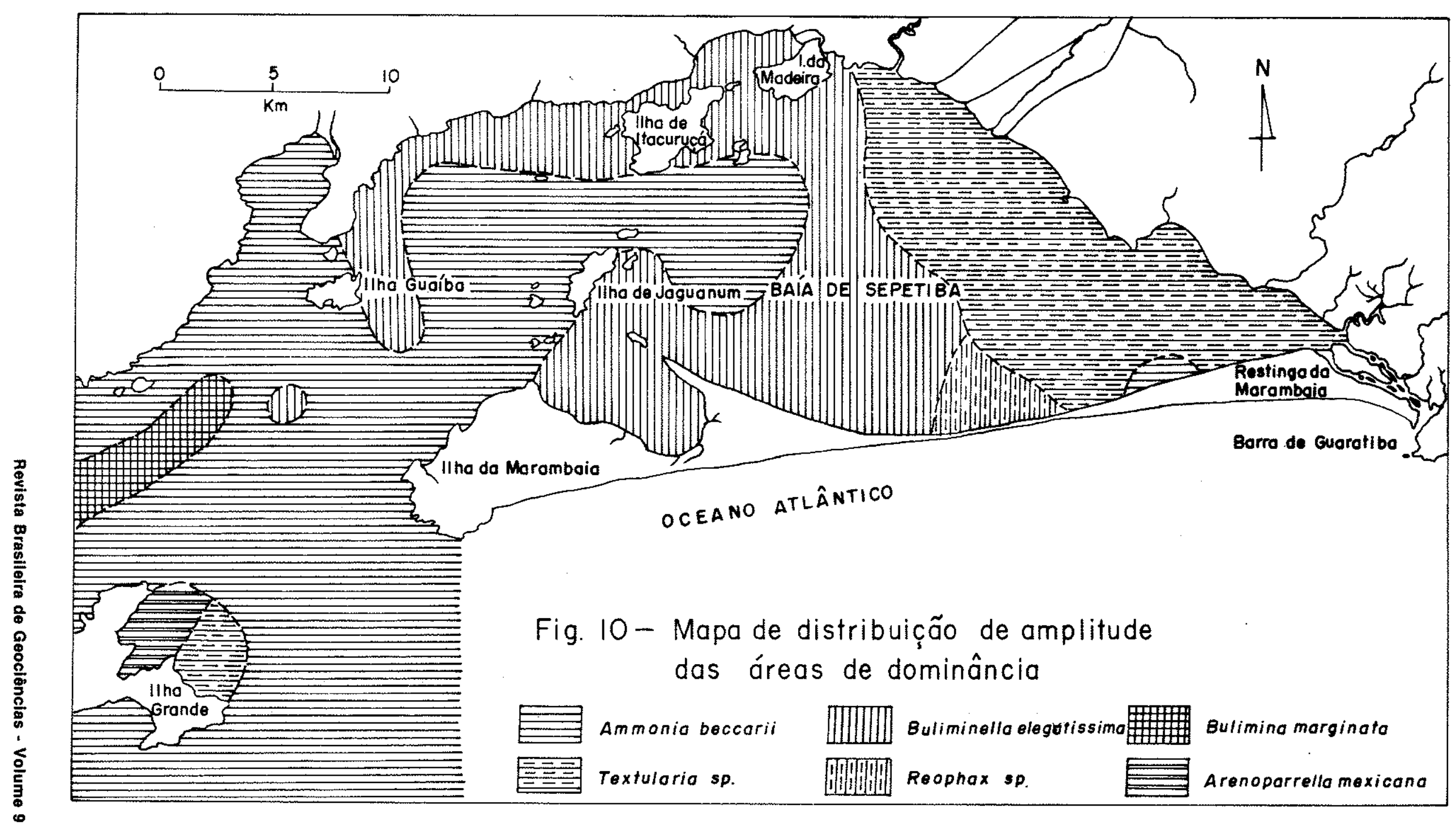




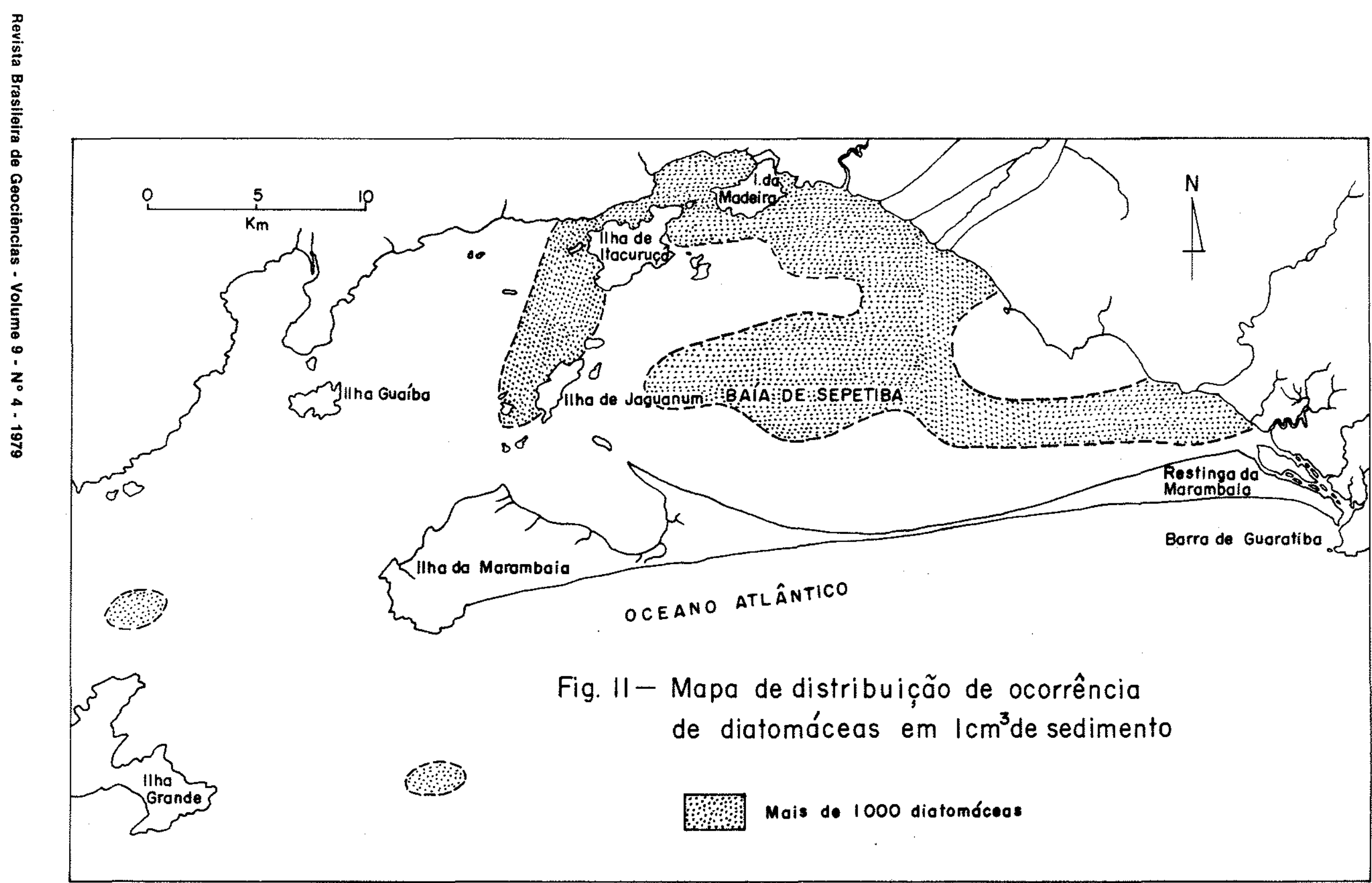

